\title{
Clinical, hormonal, and genetic characteristics of 25 Chinese patients with idiopathic hypogonadotropic hypogonadism
}

\author{
Qingxu Liu, Xiaoqin Yin and Pin Li
}

\begin{abstract}
Background: Idiopathic hypogonadotropic hypogonadism $(\mathrm{IHH})$ is a type of congenital disease caused by a variety of gene variants leading to dysfunction in the secretion of hypothalamic gonadotropin-releasing hormones (GnRHs). Clinically, IHH can be divided into Kallmann syndrome (KS) with dysosmia and normosmic idiopathic hypogonadotropic hypogonadism $(\mathrm{n} \mid \mathrm{HH})$ according to the presence or absence of an olfactory disorder.

Methods: We retrospectively evaluated $25 \mathrm{IHH}$ patients ( $8 \mathrm{KS}$ and $17 \mathrm{nIHH}$ ) who were diagnosed at the Department of Endocrinology of Shanghai Children's Hospital from 2015 to 2021. We analysed the patients' clinical data, including their hormone levels and gene sequences.

Results: All male patients exhibited small phalli, and 35\% of them exhibited cryptorchidism. A significant difference was observed in the levels of dihydrotestosterone (DHT) after human chorionic gonadotropin (HCG) stimulation $(P=0.028)$ between the KS group and the $\mathrm{nIHH}$ group. Missense variants were the major cause of $\mathrm{HH}$, and the main pathogenic genes were FGFR1, PROKR2/PROK2, and KAl1. Nine reported and 13 novel variants of six genes were identified. De novo variants were detected in $16 \mathrm{HH}$ patients; eight patients inherited the variants from their mothers, while only three patients inherited variants from their fathers. One patient had both KAl1 and PROKR2 gene variants, and another patient had two different PROKR2 gene variants. These two patients both had the hot spot variant c.533G > C (p. Trp178Ser) of the PROKR2 gene.

Conclusion: $1 \mathrm{HH}$ should be highly suspected in patients with a small phallus and cryptorchidism. Compared with $\mathrm{nIHH}$ patients, KS patients exhibited a higher level of DHT after HCG stimulation. Missense variants were the major cause of $\mathrm{HH}$, and most of the inherited variants were from their mothers who exhibited no obvious clinical symptoms. We identified 9 reported variants and 13 novel variants that led to $\mathrm{HH}$. A small proportion of patients were at risk of inheriting either the oligogenic variant or the compound heterozygous variant. The hot spot variant c.533G $>C$ (p. Trp178Ser) of PROKR2 might be involved in oligogenic inheritance and compound heterozygous inheritance. These findings provide deeper insight into the diagnosis and classification of $\mathrm{IHH}$ and will contribute to its clinical assessment.
\end{abstract}

Keywords: Idiopathic hypogonadotropic hypogonadism, Kallmann syndrome, Variant permitted by statutory regulation or exceeds the permitted use, you will need to obtain permission directly from the copyright holder. To view a copy of this licence, visit http://creativecommons.org/licenses/by/4.0/. The Creative Commons Public Domain Dedication waiver (http://creativecommons.org/publicdomain/zero/1.0/) applies to the data made available in this article, unless otherwise stated in a credit line to the data. 


\section{Background}

Idiopathic hypogonadotropic hypogonadism (IHH), also known as congenital hypogonadotropic hypogonadism $(\mathrm{CHH})$, is caused by insufficient production or secretion of hypothalamic gonadotropin-releasing hormone (GnRH) [1]. IHH can be divided into Kallmann syndrome (KS) with dysosmia and normosmic idiopathic hypogonadotropic hypogonadism (nIHH) depending on the absence or presence of olfactory disorders. The prevalence of IHH in males is approximately $1 / 10,000$, and the ratio of males to females with $\mathrm{IHH}$ is $5: 1[1,2]$. Due to the low prevalence of $\mathrm{IHH}$, only a few detailed studies on its basic clinical characteristics, related congenital malformations, hormone levels, and gene variants have been conducted using teenagers. Most of the reported studies mainly include Caucasians, which explains the known gene variant in $50 \%$ of those with $\mathrm{IHH}$ [3]; however, a large number of pathogenic genes still need to be evaluated. Previously, most patients with IHH were diagnosed and treated in late adolescence or early adulthood, as IHH was difficult to diagnose. Some studies that address the clinical and hormonal characteristics of large groups do not reveal the underlying variants. Hence, we aimed to retrospectively evaluate the clinical manifestations, genotypes, and serum hormones of $25 \mathrm{IHH}$ patients in whom gene variants were identified to better understand the mechanism underlying the development of IHH.

\section{Patients and methods}

\section{Patients}

Informed parental consent, patient consent, and approval from the Hospital Ethics Committee were obtained prior to the initiation of the study. Twenty-five sporadic patients (aged 14 to 17.5 years) with $\mathrm{IHH}$ were recruited from the Department of Endocrinology, Shanghai Children's Hospital, from 2015 to 2021. Patients who had a normal karyotype, hypothalamus and pituitary, pituitary adrenal axis, thyroid axis, and growth hormone axis were included in this study. They exhibited IHHrelated variants and clinical signs of hypogonadotropic hypogonadism. IHH can be diagnosed if the luteinizing hormone $(\mathrm{LH})$ is $\leq 8 \mathrm{IU} / \mathrm{L}$ after $60 \mathrm{~min}$ of gonadorelin stimulation or $\leq 4 \mathrm{IU} / \mathrm{L}$ after $60 \mathrm{~min}$ of triptorelin stimulation in men and when the LH is $\leq 6 \mathrm{IU} / \mathrm{L}$ after $60 \mathrm{~min}$ of the above stimulations in females $[4,5]$. We investigated the clinical manifestations, related sex hormones, and gene sequences of the patients and their parents. In our study, IHH was classified as either KS or nIHH according to the absence or presence of olfactory disorders.

\section{External genital phenotype evaluation}

We evaluated the external genital phenotypes, family history, olfactory disorders, and puberty development disorders in family members. Phallus length was compared with that of normal Chinese children. The phallus was placed in an extended state, and the length from the pubic symphysis to the top of the glans along the dorsal side of the phallus excluding the length of the foreskin was recorded as the length of the phallus. Cryptorchidism was confirmed by physical examination and ultrasound examination based on the diagnostic criteria for paediatric cryptorchidism.

\section{Hormonal analysis}

To assess testicular function, male patients underwent human chorionic gonadotropin (HCG) stimulation. All patients underwent gonadotropin-releasing hormone (GnRH) stimulation to assess hypothalamic-pituitarygonadal (HPG) axis function. Sex hormones, including anti-Mullerian hormone (AMH), inhibin B (INHB), oestradiol (E2), sex hormone-binding globulin (SHBG), basal testosterone $(\mathrm{T})$, basal dihydrotestosterone (DHT), basal $\mathrm{LH}$, peak $\mathrm{LH}$, basal follicle-stimulating hormone (FSH), peak FSH, DHT after HCG stimulation, and T after HCG stimulation, were detected. Serum LH and FSH concentrations were tested using LH and FSH detection kits (Beckman Coulter) and measured with an automatic immunoluminescence analyser (Unicel DxI 800). The serum AMH and INHB levels were detected using solid-phase sandwich enzyme-linked immunosorbent assay (ELISA) kits purchased from Guangzhou Kangrun Biotechnology Co., Ltd. E2. The T and DHT levels were tested by ELISA and measured with a USA Polar ELx800 microplate reader.

\section{IHH gene analysis}

Genomic DNA of patients and their parents was obtained from peripheral blood leukocytes via a salting out procedure. Whole exomes were amplified and sequenced to screen for variants. We searched the variant assessment database within the human gene mutation database (http://www.ncbi.nlm.nih.gov) and the ClinVar database (https://www.ncbi.nlm.nih.gov/clinvar/). PROVEAN, SIFT and Mutation Taster software were used to perform a pathogenicity analysis of amino acid changes caused by variants. The minor allele frequency (MAF) was checked for the observed variants in the Asian population. The American College of Medical Genetics and Genomics (ACMG) criteria were used for the classification of variants.

\section{Statistical analysis}

SPSS 26.0 software (manufactured by International Business Machines Corporation) was used to analyse these data. The nonparametric data were analysed using the Mann-Whitney $U$ test and are presented as median 
values. Spearman's correlation analysis was used to perform a correlation analysis. Fisher's test was applied to compare the incidence of clinical manifestations. A $P$ value of $<0.05$ was considered significant, which was indicated as follows: ${ }^{*} P<0.05$ and ${ }^{* *} P<0.01$.

\section{Results}

\section{Clinical manifestations}

Of the 25 patients with IHH (23 males and 2 females), 8 had KS, and 17 had nIHH. All male patients exhibited a small phallus, and $35 \%$ of them exhibited cryptorchidism. All patients with IHH had an absence of hypospadias or ambiguous genitalia. Of the two female patients with infantile uterus and ovary, one had a cleft lip and palate, while the other was short in stature. Twentythree male patients all had small phalli and small testes. Eight patients exhibited cryptorchidism (KS group, 2; nIHH group, 6). Six patients exhibited a short stature (KS group, 2; nIHH group, 4). Five patients developed obesity (KS group, 2; nIHH group, 3). Two patients in the nIHH group had irregular tooth alignment. No significant difference was observed in the incidence of small phallus, obesity, cryptorchidism, short stature, irregular tooth alignment, cleft palate, renal abnormalities, or syndactyly between the two groups (Table 1 and Table 2).

\section{Hormones}

All patients had a peak LH value of less than 6IU/L. No significant difference between the KS and nIHH groups was observed in the levels of AMH, INHB, SHBG, basal LH, basal FSH, basal DHT, peak LH, peak FSH, or T after HCG stimulation. In contrast, a significant difference was found in the levels of DHT after HCG stimulation $(P=0.028)$ between the two groups. The data suggested that KS patients presented higher levels of DHT after HCG stimulation than did nIHH patients (Table 2 and Fig. 1).

The correlation analysis of serum sex hormone levels in IHH patients showed that DHT after HCG stimulation was positively correlated with testicular volume

Table 1 Incidence of various clinical manifestations in patients with $\mathrm{KS}$ and $\mathrm{nlHH}$

\begin{tabular}{|c|c|c|c|c|}
\hline Clinical manifestation & KS group (8 males) & $\begin{array}{l}\text { nIHH group ( } 2 \text { females and } 15 \\
\text { males) }\end{array}$ & Total & $P$ value \\
\hline Small phallus in males & $8(100 \%)$ & $15(100 \%)$ & 23 & $>0.999$ \\
\hline Cryptorchidism in males & $2(25 \%)$ & $6(40 \%)$ & 8 & 0.657 \\
\hline Short stature & $2(25 \%)$ & $4(24 \%)$ & 6 & $>0.999$ \\
\hline Obesity & $2(25 \%)$ & $3(18 \%)$ & 5 & $>0.999$ \\
\hline Irregular tooth alignment & 0 & $2(13 \%)$ & 2 & 0.526 \\
\hline Cleft palate & 0 & $1(6 \%)$ & 1 & $>0.999$ \\
\hline Syndactyly & 0 & $1(6 \%)$ & 1 & $>0.999$ \\
\hline CHARGE syndrome & 0 & $1(6 \%)$ & 1 & $>0.999$ \\
\hline Renal abnormalities & 0 & $1(6 \%)$ & 1 & $>0.999$ \\
\hline Infantile uterus and ovary in females & 0 & $2(100 \%)$ & 2 & $>0.999$ \\
\hline
\end{tabular}

Table 2 Hormone levels and significant differences in male patients with $\mathrm{KS}$ and $\mathrm{nlHH}$

\begin{tabular}{|c|c|c|c|}
\hline Hormones & $\begin{array}{l}\text { KS group } \\
(n=8)\end{array}$ & $\begin{array}{l}\text { nIHH group } \\
(n=15)\end{array}$ & $P$ value \\
\hline $\mathrm{AMH}(\mathrm{ng} / \mathrm{mL})$ & $21.3(10-73.4)$ & $23.05(0.42-197.2)$ & 0.646 \\
\hline INHB (pg/mL) & $28.93(4.72-73.4)$ & $16.37(1.71-287.8)$ & 0.632 \\
\hline Oestradiol (pmol/L) & $73(73-197)$ & $73(73-90)$ & 0.537 \\
\hline Basal LH (IU/L) & $0.2(0.1-0.45)$ & $0.2(0.17-0.73)$ & 0.696 \\
\hline Peak LH (IU/L) & $1.24(0.31-5.86)$ & $1.49(0.53-4.12)$ & 0.764 \\
\hline Basal FSH (IU/L) & $0.54(0.25-0.81)$ & $0.54(0.24-1.89)$ & 0.740 \\
\hline Peak FSH (IU/L) & $3.08(1.86-5.65)$ & $4.3(2.28-10.81)$ & 0.084 \\
\hline Basal testosterone (nmol/L) & $0.35(0.35-1.95)$ & $0.35(0.35-1.25)$ & 0.363 \\
\hline T after HCG stimulation (nmol/L) & $1.85(0.6-7.5)$ & $1.8(0.6-10.1)$ & 0.646 \\
\hline Basal DHT (pg/ml) & $272.2(59.92-640.1)$ & $149.5(20.02-359.7)$ & 0.087 \\
\hline DHT after HCG stimulation (pg/ml) & $306.6(116.2-690.3)$ & $107.4(30.36-531.7)$ & 0.028 \\
\hline SHBG (nmol/l) & $42.3(5.5-73.4)$ & $65.9(6.4-180)$ & 0.104 \\
\hline
\end{tabular}




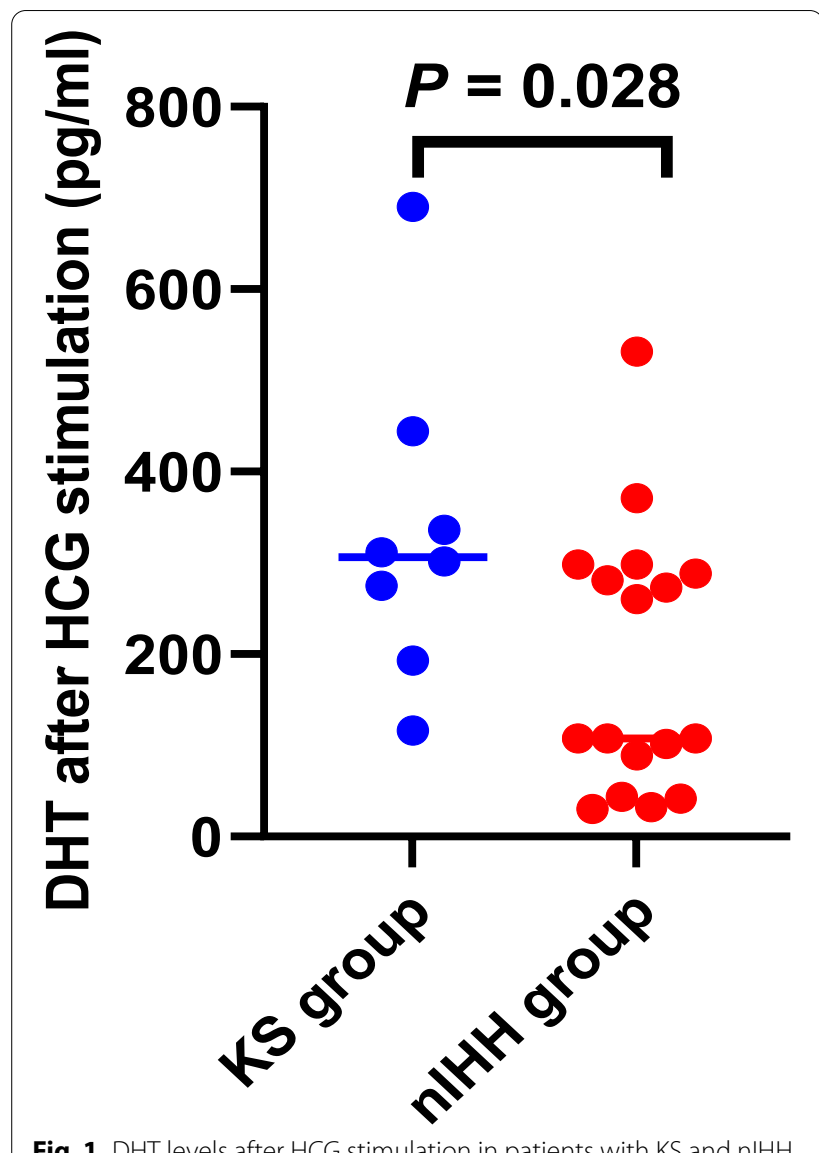

Fig. 1 DHT levels after HCG stimulation in patients with $\mathrm{KS}$ and $\mathrm{nIHH}$

$(r=0.569, P<0.01)$ and basal DHT levels $(r=0.903$, $P<0.01)$. BMI was negatively correlated with peak FSH $(r=-0.414, P<0.05)$ and SHBG $(r=-0.722, P<0.01)$. T levels after HCG stimulation were positively correlated with AMH $(r=0.543, P<0.01)$, INHB $(r=0.646, P<0.01)$, and peak LH levels $(r=0.506, P<0.05)$. Peak FSH was positively correlated with peak LH levels $(r=0.552$, $P<0.01)$. A close positive correlation was observed between AMH and INHB levels $(r=0.943, P<0.01)$ (Fig. 2).

\section{Molecular studies}

The proportions of various gene variants in patients were as follows: KAl1 gene (4/25), PROKR2 (8/25), PROK2 $(2 / 25)$, FGFR1 (11/25), CHD7 (1/25), and SEMA3A $(1 / 25)$. Nine reported pathogenic and 13 novel variants of six genes were identified, among which the new missense variants were predicted as harmful by multiple protein function prediction software programs. De novo variants were found in $16 \mathrm{IHH}$ patients; eight patients inherited the variants from their mothers, while only three patients inherited variants from their fathers, who carried heterozygous variants. Four KAl1 gene variants (two nonsense variants and two frameshift variants caused by deletion) and four FGFR1 frameshift variants (one duplication, one insertion, and two deletion) resulted in protein synthesis termination. Of the 11 (73\%) FGFR1 variants, 8 were novel variants. Two novel variants in the PROK2 gene were detected in two patients, and three reported pathogenic missense variants of the PROKR2 gene were detected in eight patients. One patient had a reported pathogenic variant in the CHD7 gene, while the other patient had a novel missense variant in the SEMA3A gene. One patient had KAl1 and PROKR2 gene variants simultaneously, while the other patient had two kinds of PROKR2 gene variants. These two patients both had the hot spot variant c.533G >C (p. Trp178Ser) of the PROKR2 gene. This variant was also found in the other four patients (Table 3 ).

\section{Discussion}

$\mathrm{IHH}$ is a disease with genetic and clinical heterogeneity caused by dysfunction of GnRH synthesis, secretion, or action. An obvious phenotypic overlap was observed between $\mathrm{nIHH}$ and KS in our study. Different pathogenic genes produced similar clinical phenotypes, but the same pathogenic gene had different phenotypes. Patients with KS experience a loss or decline of olfactory function. The IHH patients in our study had a variety of reproductive and nonreproductive system phenotypes; the male patients had a small phallus, small testes, or cryptorchidism, while the female patients often exhibited a lack of secondary sexual characteristics. These clinical features often manifest after puberty; hence, it is difficult to diagnose IHH in children. Small phallus and cryptorchidism were related to the lack of androgen during the period of foetal development and were the most common reproductive system phenotypes for male teenagers, which were more serious than those of adult patients. Inguinal cryptorchidism was more common because testicular descent from the inguinal to scrotal stage is mainly driven by androgen [6]. In addition to the common olfactory abnormalities of KS, a series of related abnormalities are found in the nonreproductive systems of IHH children, including obesity, short stature, renal dysplasia, cleft palate, irregular tooth alignment, and syndactyly, which laid the foundation for the research of hormones and genes.

The sex hormone levels of the KS group and nIHH group were generally low in our study, especially the peak LH, peak FSH, and T levels after HCG stimulation. KS patients presented higher levels of DHT after HCG stimulation than did $\mathrm{nIHH}$ patients (median: $306.6 \mathrm{pg} / \mathrm{ml}$ vs. $107.4 \mathrm{pg} / \mathrm{ml}$ ). This might be due to the higher proportion of cryptorchidism leading to the lower androgen level in the nIHH group. In addition, DHT after HCG stimulation was positively correlated with testicular volume 

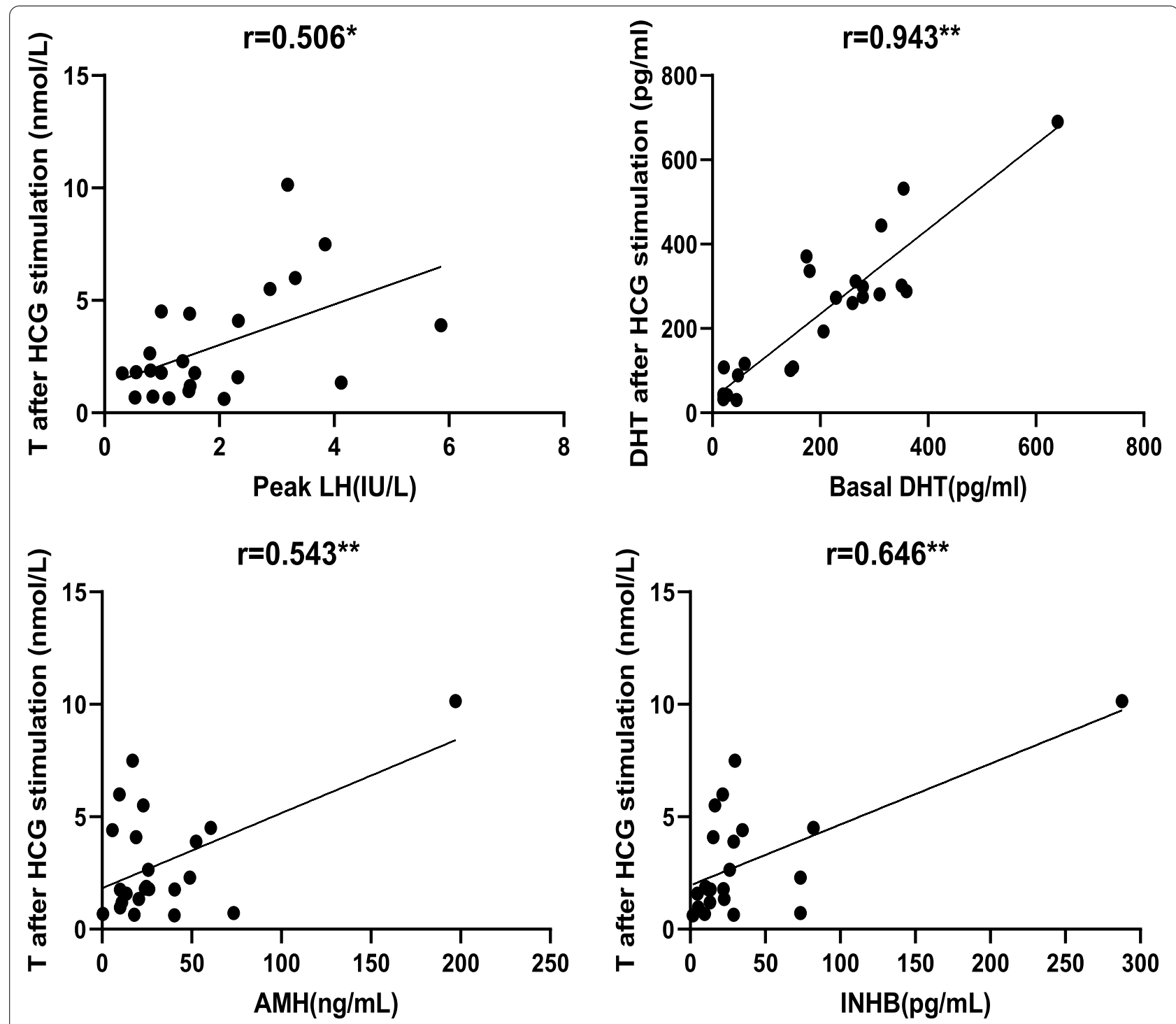

Fig. 2 Correlation analysis of serum hormones in patients with $1 \mathrm{HH}$

and basal DHT. AMH and INHB could be detected in patients with $\mathrm{IHH}$, which indicated normal testicular function. The testes of $\mathrm{IHH}$ patients responded poorly to HCG stimulation. The poor response to HCG stimulation might be related to the lack of gonadotropin stimulation for a long time. The correlation analysis of sex hormones showed that the correlation between T after HCG stimulation and AMH or INHB was higher than that with peak $\mathrm{LH}$, and the correlation between AMH and INHB was extremely strong; therefore, AMH and INHB had a stronger predictive effect on T levels after HCG stimulation compared with peak LH levels.

Maintenance of the normal function of GnRH neurons requires the development, migration, secretion, and function of normal GnRH neurons, which are regulated by several types of genes [7, 8]. The KAl1 (ANOS1) gene is the first pathogenic gene of $\mathrm{KS}$, which is inherited through the X-linked recessive mode. Anosmin-1 protein, encoded by the ANOS1 gene, is a type of extracellular matrix-related protein that plays an important role in the development and migration of olfactory nerve and GnRH neurons through the FGFR1 signalling pathway. Loss-of-function variants of the ANOS1 gene lead to KS, and its clinical phenotypes are relatively severe, including complete loss of puberty, infertility, cryptorchidism, and small phallus. In our study, c.1891C > T(p. Arg631*) and c. $1267 \mathrm{C}>\mathrm{T}(\mathrm{p}$. Arg423*) were the two reported variants $[9,10]$, while c.1525delA(p. Ser509fs) and c.1524del 


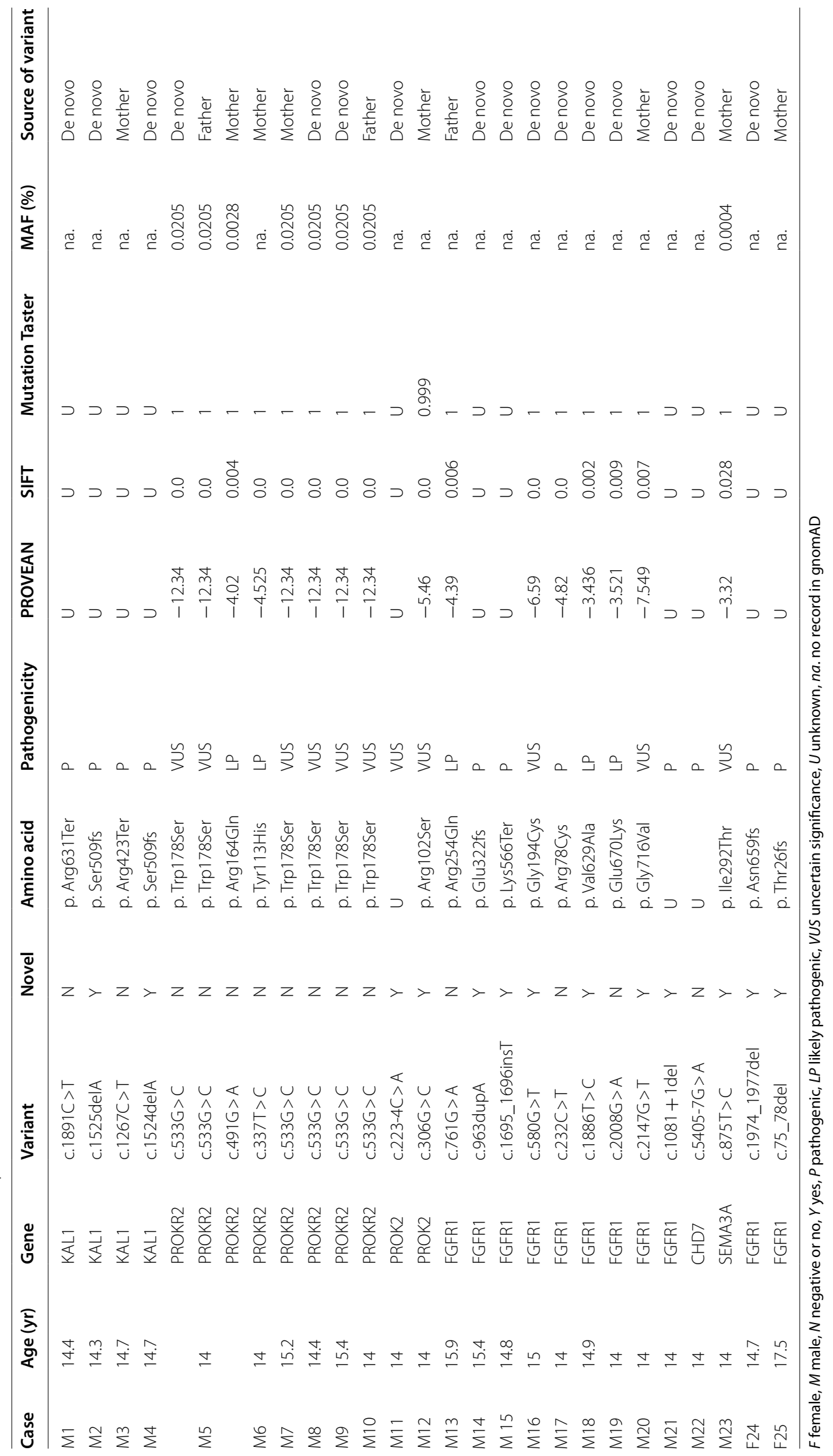


A(p. Ser509fs) were the two novel variants, which led to KS with small phallus, cryptorchidism, and obesity. Four kinds of KAl1 gene variants resulted in the termination of protein synthesis, the production of truncated protein, or the activation of nonsense-mediated mRNA degradation, which destroyed the integrity of the protein structure and led to the loss of protein function.

Prokineticin-2 (PROK2) is a protein that plays an important role in the development of olfactory nerve and $\mathrm{GnRH}$ neurons and the regulation of physiological rhythm through its receptor PROKR2. Meanwhile, KS patients present with homozygous, compound heterozygous, and heterozygous gene variants in the PROKR2 and PROKR2 genes, which can be passed down through autosomal dominant or oligogenic inheritance [11]. In our study, $40 \%$ of patients developed PROK2/PROKR2 variants, which was significantly higher than the $9 \%$ in the Caucasian population [12]. Most of them were missense variants in patients with a nonobvious phenotype [13]. In our study, only one patient had a splicing mode variant; the rest of the patients had missense variants. Some patients exhibited olfactory dysosmia and obesity, which was consistent with the clinical manifestations of extreme obesity in patients with PROKR2 variants reported in previous studies [14]. Two novel variants of the PROK2 gene were found in patients with anosmia, obvious small phallus, and low levels of sex hormones. c. $223-4 \mathrm{C}>\mathrm{A}$ might affect the normal splicing of exons in the PROK2 gene, and the novel variant c.306G > C (p. Arg102Ser) was predicted to be harmful by multiple software programs. A few missense variants were detected in patients with a PROK2 gene, and most of the missense variants recorded in the ClinVar database were pathogenic. Three kinds of missense variants in the PROKR2 gene were found in eight patients. c.337 T $>\mathrm{C}$ (p. Tyr113His) significantly decreased the receptor expression level and reduced intracellular calcium mobilization, resulting in protein instability and poor biological function [13]. c.491G > A (p. Arg164Gln) destroyed the interaction between the IL2 domain and G-protein, inhibited Gq-protein signal activity, and weakened $G$ protein-coupled receptors [11]. The hot spot variant c.533G > C (p. Trp178Ser) was found in six patients and located in the transmembrane domain of the protein, which could significantly reduce the release of ionized calcium and the signal activity [15].

The FGFR1 gene is expressed in many tissues and plays an important role in the development of embryonic olfactory nerve and GnRH neurons mainly through the FGF/FGFR1 signalling pathway [16]. FGFR1 signalling is essential for the migration, secretion, or survival of hypothalamic GnRH neurons and is widely expressed in the nervous and skeletal systems. The FGFR1 gene is inherited through an autosomal dominant mode [17].
Loss of function can lead to both $\mathrm{nIHH}$ and KS, and more than 200 variants of the FGFR1 gene have been found in patients with IHH [18]. The FGFR1 gene had the highest variant frequency, approximately $44 \%$ in our study, which was higher than that $(10 \%)$ in the Caucasian population [19]. Its variant can cause cleft lip and palate, short stature, and bone dysplasia [20, 21]. Among the 11 FGFR1 variants reported in our study, c.761G > A (p. Arg254Gln), c.232C > T (p. Arg78Cys), and c.2008G > A (p. Glu670Lys) were found to be pathogenic variants [5, 22]. Among the other eight novel variants, c.963dupA (p. Glu322fs), c.1695_ 1696insT (p. Lys566*), c.1974_ 1977del (p. Asn659fs), and c.75_ 78del (p. Thr26fs) caused the termination of protein synthesis, the production of truncated protein, or activation of nonsensemediated mRNA degradation, which destroyed the structural integrity of the FGFR1 protein and led to the loss of FGFR1 protein function. The software predicted that the variant c.1081+1del would destroy the highly conserved donor splicing site activity in exon 8 and then lead to abnormal splicing, resulting in changes in the function of the protein encoded by the gene. Amino acid conservation analysis showed that the wild-type amino acid Val629 was conserved in 100 vertebrates tested, which indicated that the variant c.1886 T $>C$ (p. Val629Ala) might not be tolerated and has adverse effects on the structure and function of the protein. In addition, the c.580G > T (p. Gly194Cys) and c.2147G > T (p. Gly$716 \mathrm{Val}$ ) variants were identified by the software as harmful. In previous studies, the phenotype of the FGFR1 gene was not completely dominant, and most of the variants were inherited from a normal father or mother. However, most of the patients in our study had de novo variants; one patient inherited the variants from his father, while the other patient inherited the variants from her mother. Two female patients had a frameshift variant of the FGFR1 gene, which showed an infantile uterus and ovary. In the group with a nonreproductive phenotype, variants in the FGFR1 gene were found in one patient with cleft lip and palate, which was consistent with the report of a previous study [20]. Another patient presented with a renal cyst and short stature. Therefore, anosmia, sexual dysplasia, irregular tooth alignment, cleft lip and palate, syndactyly, and renal abnormalities were common phenotypes of IHH patients with FGFR1 gene variants.

The CHD7 gene is located on chromosome $8 \mathrm{q} 12.1$ and is autosomal dominant, encoding chromosomal helicase DNA-binding protein 7 . It has low to moderate expression in all tissues, including the lesion sites of KS: olfactory bulb, olfactory tract, and hypothalamus. CHARGE syndrome includes a series of organ and system abnormalities [23]. Both KS and CHARGE syndrome can be characterized by anosmia and 
hypogonadotropic hypogonadism, which means that KS is part of the phenotypic spectrum of CHARGE syndrome. The greater the expression of the CHD7 gene is, the more obvious the clinical features of patients with $\mathrm{IHH}$, especially the symptoms of cryptorchidism, small phallus, and hypospadias in childhood [24]. Only one patient had a hot spot of intron variant c.5405-7G > A. In our study, it was reported to be pathogenic [25]; this finding was consistent with the results of two previous studies, which indicated that the CHD7 variant was not the primary cause of KS because only $3-5 \%$ of $\mathrm{nIHH} /$ KS patients had a CHD7 variant $[23,26]$.

SEMA3A is a reported pathogenic gene of IHH that is inherited through an autosomal dominant mode [27]. SEMA3A can affect the function of the hypothalamus pituitary gonad axis by regulating the differentiation and maturation of nerve cells, either alone or in combination with other factors (such as FGFR1) [28]. These transcription factors are widely expressed in the nervous system, and their functional defects can cause a nonreproductive phenotype, such as short stature, mental retardation, obesity, and abnormal vision. One patient presented small phallus, cryptorchidism, and irregular tooth alignment and had a novel missense variant c.875 T > C (p. Ile292Thr) in the SEMA3A gene, which was identified by software as harmful.

We described the clinical characteristics of Chinese IHH patients and the variant frequency of known pathogenic genes. We found pathogenic variants in six genes and expanded the expression profile of $\mathrm{IHH}$ pathogenic genes. An increasing number of scholars agree that GnRH deficiency is not strictly a single-gene disease but may be a double-gene or oligogenic genetic disease. Approximately $11.3 \%$ of patients with $\mathrm{IHH}$ carry two or more pathogenic gene variants, and the genetic model of oligoenes provides new insights [29]. In addition, most patients with IHH have heterozygous gene variants, and these variants are inherited from parents with a normal phenotype [30]. One patient had a novel de novo variant of KAl1 (c.1524delA, p. Ser509fs) and a hot spot variant of PROKR2 (c.533G > C, p. Trp178Ser) simultaneously. However, the clinical phenotype caused by the two gene variants was not more serious than that caused by a single gene variant because the patient manifested small phallus and small testes without a nonreproductive phenotype. In addition, one patient had two previously reported variants in the PROKR2 gene, namely, c.491G > A (p. Arg164Gln) and c.533G $>C$ (p. Trp178Ser). The patient's phenotype was relatively severe, and he had a short stature without obvious small phallus and small testes. These results indicated that the hot spot variant c.533G $>C$ (p. Trp178Ser) of the PROKR2 gene might be involved in oligogenic inheritance and the complex heterozygous pathogenesis of IHH genes.

In this study, we identified nine reported gene variants, and we detected 13 novel variants: c.1525del A(p. Ser509fs) and c.1524del A(p. Ser509fs) variants in the KAl1 gene; c.223-4C >A and c.306G >C(p. Arg102Ser) variant in the PROK2 gene: c.963dup A (p. Glu322fs), c.1695_1696insT(p. Lys566Ter), c.580G > T(p. Gly194Cys), c. 1886 T > C(p. Val629Ala), c.2147G > T(p. Gly716Val), c.1081+1del, c.1974_ 1977del (p. Asn659fs), and c.75_ 78del (p. Thr26fs) variants in the FGFR1 gene; and c.875 T >C (p. Ile292Thr) variant in the SEMA3A gene. The 13 novel variants identified in our study cause different types of IHH. These findings will provide deeper insight into the diagnosis of $\mathrm{IHH}$ and contribute to its clinical assessment.

The findings of this study have to be seen in light of some limitations. It is difficult to obtain samples for rare diseases, and the significant difference in hormone levels might be affected by the small sample size in our study. All patients in our study were sporadic, and there were no familial patients. Due to the limitations of genetic diagnosis, although many genes have been found to be associated with GnRH deficiency, the genetic basis of more than half of patients with IHH remains unknown.

\section{Conclusions}

Abnormalities in the KAl1, PROKR2, PROK2, FGFR1, CHD7, or SEMA3A genes could cause IHH with or without nonreproductive manifestations. IHH should be highly suspected in patients with small phallus and cryptorchidism; moreover, nIHH was more common than KS. We demonstrated that $\mathrm{nIHH}$ and KS patients could not be distinguished based on the levels of their basal hormones, peak hormones after GnRH stimulation, or T after HCG stimulation. However, KS patients exhibited higher levels of DHT after HCG stimulation. We identified 9 reported variants and 13 novel variants of six genes that could result in IHH with different symptoms. A small proportion of patients might be affected by oligogenic inheritance or compound heterozygous inheritance. These findings provide deeper insight into the diagnosis of $\mathrm{IHH}$ and will contribute to its clinical assessment.

\footnotetext{
Abbreviations

KS: Kallmann syndrome; IHH: Isolated hypogonadotropic hypogonadism; $\mathrm{nlHH}$ : Normosmic idiopathic hypogonadotropic hypogonadism; $\mathrm{CHH}$ : Congenital hypogonadotropic hypogonadism; INHB: Inhibin B; SHBG: Sex hormone-binding globulin; LH: Luteinizing hormone; FSH: Follicle-stimulating hormone; T: Testosterone; DHT: Dihydrotestosterone; E2: Oestradiol; HCG: Human chorionic gonadotropin; AMH: Anti-Mullerian hormone; GnRH: Gonadotropin-releasing hormone; HPG: Hypothalamic-pituitary-gonadal; MAF: Minor allele frequency; ACMG: American College of Medical Genetics and Genomics.
} 


\section{Acknowledgements}

We are grateful to Wuhen Xu for providing research platform support and critical comments on the experiments.

\section{Authors' contributions}

Liu Q designed the experiments and analysed the data. Li P provided the reagents/materials/analysis tools. Yin X helped with the analysis and presentation of data. All authors read and approved the final manuscript.

\section{Funding}

This work was supported by the National Natural Science Foundation of China (81871131), the Key Subject Program of the Shanghai Municipal Commission of Health and Family Planning (2016ZB0102), the Yangtze River Delta Project of the Shanghai Science and Technology Commission (13495810300), and the major project of Shanghai Shenkang Hospital Development Center (SHDC2020CR2058B).

\section{Availability of data and materials}

All data generated or analysed during this study are included in the published article. The datasets used and/or analysed during the current study are available from the corresponding author upon reasonable request.

\section{Declarations}

\section{Ethics approval and consent to participate}

The research was performed in accordance with the principles of the Declaration of Helsinki. The study was approved by the ethics committee of Shanghai Children's Hospital Affiliated with Shanghai Jiao Tong University (2020R083 - F02, Shanghai, China). Informed consent was obtained from all patients prior to their participation in this study.

\section{Consent for publication}

The authors and participants agree to the publication of this manuscript.

\section{Competing interests}

The authors declare that they have no competing interests.

Received: 2 September 2021 Accepted: 19 January 2022

Published online: 28 January 2022

\section{References}

1. Bianco S, Kaiser U. The genetic and molecular basis of idiopathic hypogonadotropic hypogonadism. Nat Rev Endocrinol. 2009;5(10):569-76.

2. Beate K, Joseph N, Nicolas DR, Wolfram K. Genetics of isolated hypogonadotropic hypogonadism: role of $\mathrm{GnRH}$ receptor and other genes. Int J Endocrinol. 2012;2012:147893.

3. Miraoui H, Dwyer A, Sykiotis G, Plummer L, Chung W, Feng B, et al. Mutations in FGF17, IL17RD, DUSP6, SPRY4, and FLRT3 are identified in individuals with congenital hypogonadotropic hypogonadism. Am J Hum Genet. 2013;92(5):725-43.

4. Jiangfeng $M$, Xueyan $W$, Jingtao D. Interpretation of expert consensus on diagnosis and treatment of idiopathic hypogonadotropic hypogonadism. Chin J Intern Med. 2016:36(3):204-7.

5. Pitteloud N, Meysing A, Quinton R, Acierno J, Dwyer A, Plummer L, et al. Mutations in fibroblast growth factor receptor 1 cause Kallmann syndrome with a wide spectrum of reproductive phenotypes. Mol Cell Endocrinol. 2006;254-255:60-9.

6. Hutson J, Li R, Southwell B, Newgreen D, Cousinery M. Regulation of testicular descent. Pediatr Surg Int. 2015;31(4):317-25.

7. Teixeira L, Guimiot F, Dodé C, Fallet-Bianco C, Millar R, Delezoide A, et al. Defective migration of neuroendocrine $\mathrm{GnRH}$ cells in human arrhinencephalic conditions. J Clin Invest. 2010;120(10):3668-72.

8. Forni P, Taylor-Burds C, Melvin V, Williams T, Williams T, Wray S. Neural crest and ectodermal cells intermix in the nasal placode to give rise to $\mathrm{GnRH}-1$ neurons, sensory neurons, and olfactory ensheathing cells. J Neurosci. 2011;31(18):6915-27.

9. Sato N, Katsumata N, Kagami M, Hasegawa T, Hori N, Kawakita S, et al. Clinical assessment and mutation analysis of Kallmann syndrome
1 (KAL1) and fibroblast growth factor receptor 1 (FGFR1, or KAL2) in five families and 18 sporadic patients. J Clin Endocrinol Metab. 2004:89(3):1079-88

10. Fan $Y$, Zhang $X$, Wang L, Wang R, Huang Z, Sun Y, et al. Diagnostic application of targeted next-generation sequencing of 80 genes associated with disorders of sexual development. Sci Rep. 2017;7:44536.

11. Cox K, Oliveira L, Plummer L, Corbin B, Gardella T, Balasubramanian R, et al. Modeling mutant/wild-type interactions to ascertain pathogenicity of PROKR2 missense variants in patients with isolated $\mathrm{GnRH}$ deficiency. Hum Mol Genet. 2018;27(2):338-50.

12. Sarfati J, Dodé C, Young J. Kallmann syndrome caused by mutations in the PROK2 and PROKR2 genes: pathophysiology and genotype-phenotype correlations. Front Horm Res. 2010;39:121-32.

13. Cole L, Sidis Y, Zhang C, Quinton R, Plummer L, Pignatelli D, et al. Mutations in prokineticin 2 and prokineticin receptor 2 genes in human gonadotrophin-releasing hormone deficiency: molecular genetics and clinical spectrum. J Clin Endocrinol Metab. 2008;93(9):3551-9.

14. Dodé C, Teixeira L, Levilliers J, Fouveaut C, Bouchard P, Kottler M, et al. Kallmann syndrome: mutations in the genes encoding prokineticin-2 and prokineticin receptor-2. PLoS Genet. 2006:2(10):e175.

15. Monnier C, Dodé C, Fabre L, Teixeira L, Labesse G, Pin J, et al. PROKR2 missense mutations associated with Kallmann syndrome impair receptor signalling activity. Hum Mol Genet. 2009;18(1):75-81.

16. Semple R, Topaloglu A. The recent genetics of hypogonadotrophic hypogonadism - novel insights and new questions. Clin Endocrinol. 2010;72(4):427-35.

17. Dodé C, Levilliers J, Dupont J, De Paepe A, Le Dû N, Soussi-Yanicostas N, et al. Loss-of-function mutations in FGFR1 cause autosomal dominant Kallmann syndrome. Nat Genet. 2003;33(4):463-5.

18. Gonçalves C, Bastos M, Pignatelli D, Borges T, Aragüés J, Fonseca F, et al. Novel FGFR1 mutations in Kallmann syndrome and normosmic idiopathic hypogonadotropic hypogonadism: evidence for the involvement of an alternatively spliced isoform. Fertil Steril. 2015;104(5):1261-1267. e1261.

19. Villanueva C, de Roux N. FGFR1 mutations in Kallmann syndrome. Front Horm Res. 2010;39:51-61.

20. Jarzabek K, Wolczynski S, Lesniewicz R, Plessis G, Kottler M. Evidence that FGFR1 loss-of-function mutations may cause variable skeletal malformations in patients with Kallmann syndrome. Adv Med Sci. 2012;57(2):314-21.

21. Xu H, Niu Y, Wang T, Liu S, Xu H, Wang S, et al. Novel FGFR1 and KISS1R mutations in Chinese Kallmann syndrome males with cleft lip/palate. Biomed Res Int. 2015;2015:649698.

22. Costa-Barbosa F, Balasubramanian R, Keefe K, Shaw N, Al-Tassan N Plummer $\mathrm{L}$, et al. Prioritizing genetic testing in patients with Kallmann syndrome using clinical phenotypes. J Clin Endocrinol Metab. 2013;98(5):E943-53.

23. Kim H, Kurth I, Lan F, Meliciani I, Wenzel W, Eom S, et al. Mutations in CHD7, encoding a chromatin-remodeling protein, cause idiopathic hypogonadotropic hypogonadism and Kallmann syndrome. Am J Hum Genet. 2008;83(4):511-9.

24. Bergman J, Janssen N, Hoefsloot L, Jongmans M, Hofstra R, van Ravenswaaij-Arts C. CHD7 mutations and CHARGE syndrome: the clinical implications of an expanding phenotype. J Med Genet. 2011;48(5):334-42.

25. Legendre $M$, Rodriguez-Ballesteros $M$, Rossi M, Abadie $V$, Amiel J, Revencu $\mathrm{N}$, et al. CHARGE syndrome: a recurrent hotspot of mutations in CHD7 IVS25 analyzed by bioinformatic tools and minigene assays. Eur J Hum Genet. 2018;26(2):287-92.

26. Jongmans M, van Ravenswaaij-Arts C, Pitteloud N, Ogata T, Sato N, Claahsen-van der Grinten H, et al. CHD7 mutations in patients initially diagnosed with Kallmann syndrome--the clinical overlap with CHARGE syndrome. Clin Genet. 2009;75(1):65-71.

27. Hanchate N, Giacobini P, Lhuillier P, Parkash J, Espy C, Fouveaut C, et al. SEMA3A, a gene involved in axonal pathfinding, is mutated in patients with Kallmann syndrome. PLoS Genet. 2012;8(8):e1002896.

28. Georgopoulos N, Koika V, Galli-Tsinopoulou A, Spiliotis B, Adonakis G, Keramida M, et al. Renal dysgenesis and KAL1 gene defects in patients with sporadic Kallmann syndrome. Fertil Steril. 2007;88(5):1311-7.

29. Sykiotis G, Plummer L, Hughes V, Au M, Durrani S, Nayak-Young S, et al. Oligogenic basis of isolated gonadotropin-releasing hormone deficiency. Proc Natl Acad Sci U S A. 2010;107(34):15140-4. 
30. Boehm U, Bouloux P, Dattani M, de Roux N, Dodé C, Dunkel L, et al. Expert consensus document: European Consensus Statement on congenital hypogonadotropic hypogonadism--pathogenesis, diagnosis and treatment. Nat Rev Endocrinol. 2015;11(9):547-64.

\section{Publisher's Note}

Springer Nature remains neutral with regard to jurisdictional claims in published maps and institutional affiliations.

- fast, convenient online submission

- thorough peer review by experienced researchers in your field

- rapid publication on acceptance

- support for research data, including large and complex data types

- gold Open Access which fosters wider collaboration and increased citations

- maximum visibility for your research: over 100M website views per year

At BMC, research is always in progress.

Learn more biomedcentral.com/submissions 